\title{
Yozgat ilinde alerjik kontakt dermatitli olgularda yama testi sonuçları
}

\author{
Patch test results in patients with allergic contact dermatitis in Yozgat
}

\section{Emine Çölgeçen Özel, Kemal Özyurt*}

Bozok Üniversitesi Tıp Fakültesi, Deri ve Zührevi Hastalıklar Anabilim Dalı, Yozgat, Türkiye *Sütçü İmam Üniversitesi Tıp Fakültesi, Deri ve Zührevi Hastalıklar Anabilim Dalı, Kahramanmaraș, Türkiye

\section{Özet}

Amaç: Yama testi hem alerjik kontakt dermatit (AKD) tanııının konulması hem de nedenin ortaya çıkartılarak hastalığın önlenmesi ve hastanın bilgilendirilmesi açılarından değerli bir testtir.

Gereç ve Yöntem: AKD tanısı alan 94'ü (\%56) kadın, 74'ü (\%44) erkek toplam 168 hastaya 28 maddelik Avrupa standart serisi (ASS) ile yama testi yapıldı. Test sonuçları uygulamadan 48 ve 72 saat sonra Uluslararası Kontakt Dermatit Araştırma Grubu'nun önerisine göre okundu. Bulgular: Hastaların büyük çoğunluğunun $(\% 64,3) 16-45$ yaş grubunda yer aldığı ve kontakt dermatit lezyonlarının en sık ellerde $(\% 57,1)$ yerleştiği görüldü. Seksen altı olguda $(\% 51,1)$ bir veya daha fazla maddeye karşı pozitif reaksiyon elde edildi. En sık duyarlandıııının nikel sülfat olduğu $(\% 20,2)$, bunu potasyum dikromat $(\% 8,3)$, kobalt klorit $(\% 7,1)$, koku karışımı $(\% 7,1)$, parafenilendiamin baz $(\% 6)$, paraben karışımı (\%3,6), N-isopropil-N-fenil-4-fenilendiamin (\%3,6), yün alkolleri $(\% 3,6)$, formaldehit $(\% 3,6)$, quaternium15 $(\% 3,6)$ takip etmekteydi. Nikel sülfat ile pozitif reaksiyon veren olgular çoğunlukla genç yaş grubundaki kadınlardı. Kliokinol ve metildibromoglutaronitril ile hiçbir olguda pozitif reaksiyon görülmezken, neomisin sülfat, epoksi reçine, 4-tert-butilfenolformaldehit reçine, seskuiterpenlakton karışımı, primin, 5-kloro-2-metil-4-izotiazol-3-1, budesonid, "lyral" gibi maddeler daha nadir $(\% 1,2)$ alerjen olarak saptandı.

Sonuç: Bölgemizde daha önce benzer bir çalışma yapılmamış olması nedeni ile çalısmamız Yozgat ilinde AKD tanısıyla deri yama testi yapılan hastaların kontakt alerjen profili hakkında bilgi vermektedir. ASS ile en sık saptanan alerjenler ve sıklık oranları, Türkiye'nin çeşitli illerindeki merkezler arasında değişkenlik göstermektedir. Kontakt alerjen profilindeki bölgesel farklııkların, aynı zaman diliminde yapılacak yeni çalışmalarla değerlendirilmesi sonucunda ülkemize ait bir standart seri oluşturulabilir. (Türkderm 2013; 47: 161-5)

Anahtar Kelimeler: Alerjik kontakt dermatit, yama testi, Avrupa standart serisi

\section{Summary}

Background and Design: Patch testing is valuable in the diagnosis of allergic contact dermatitis (ACD) as well as in determining the causative agent and, thus, is helpful in prevention of the disease and also provides information for the patient.

Materials and Methods: Hundred and sixty-eight patients (94 female and 74 male) with ACD were patch tested with European standard series (ESS). Patch test results were assessed according to International Contact Dermatitis Research Group recommendations at 48 and 72 hours after initial application.

Results: Of the patients, $64.3 \%$ were between $16-45$ years of age and majority of the lesions (57.1\%) were localized on the hands. A total of $86(51.1 \%)$ patients had one or more positive patch test reactions. The most common allergens were nickel sulfate $(20.2 \%)$ followed by potassium dichromate (8.3\%), cobalt chloride (7.1\%), fragrance mix (7.1\%), paraphenylendiamine base (6\%), paraben mix 3.6\%), N-isopropyl$\mathrm{N}$-phenyl-p-phenylenediamine (3.6\%), wool alcohols (3.6\%), formaldehyde (3.6\%), and quaternium-15 (3.6\%). Positive reactions to nickel sulfate were more common among women, especially among those in younger group. Frequency of contact allergy to neomycin sulfate,

Yazışma Adresi/Address for Correspondence: Dr Emine Çölgeçen, Bozok Üniversitesi Tıp Fakültesi, Deri ve Zührevi Hastalıklar Anabilim Dalı, Yozgat, Türkiye GSM: +90 5054895318 E-posta: drecolgecen@hotmail.com Geliş Tarihi/Received: 01.11.2012 Kabul Tarihi/Accepted: 08.01.2013 
epoxy resin, 4-tert-butylphenolformaldehyde resin, sesquiterpenelactone mix, primin, 5-chloro-2-methyl-4-isothiazolin-3-1, budesonide, and lyral were relatively low (1.2\%), while no positive reaction was obtained to clioquinol and methyldibromoglutaronitrile in any case.

Conclusion: Since no similar study has been previously performed in our area, this study provides information about contact allergen profile in patients underwent skin patch test with a diagnosis of ACD in Yozgat. The most frequent allergens detected with ESS and frequency rates may vary among different facilities in various cities in Turkey. A standard series for our country may be created after assessment of regional variability by new studies conducted in the same time zone. (Turkderm 2013; 47: 161-5)

Key Words: Allergic contact dermatitis, patch test, European standard series

\section{Giriş}

Kontakt dermatit, iritan veya alerjik maddelerin deriye teması ile oluşan inflamatuvar bir cevaptır. Dermatoloji polikliniklerine başvuran hastaların yaklaşık \%5-10'unu kontakt dermatitli hastalar oluşturmakta ve prevalansının genel olarak \%1,5-5,4 arasında olduğu tahmin edilmektedir. Kontakt dermatitler oluşum mekanizmasına göre irritan kontakt dermatit (IKD) ve alerjik kontakt dermatit (AKD) olarak iki gruba ayrılmaktadır. iKD'ler olguların yaklaşık \%80'ini oluştururken geri kalan \%20 kısmını AKD'ler oluşturmaktadır. Kontakt dermatite neden olan faktörler kişisel özelliklere, meslek ve çevre şartlarına, sosyo-ekonomik koşullara ve ülkelere göre farklııılar göstermektedir1-3.

AKD alerjen madde ile daha önce duyarlanmış kişilerde aynı madde ile daha sonra karşılaşılması durumunda oluşan geç tip aşırı duyarlıık reaksiyonudur. AKD'li hastalarda etyolojik ajanın saptanması, hastalığın sağaltımında ve tekrarının önlenmesinde önemlidir. Bu nedenle yama testi yaygın olarak kullanılmaktadır.

Illk kez Jadassohn'nun tanımladığı ve daha sonra Bloch tarafından kullanıma konan yama testi, kişinin test edilen maddeye karşı duyarlıı̆̆ını göstermektedir. Yama testi, hikaye ve klinik görünüm ile AKD tanısı düşünülen hastalara alerjenlerin belirli konsantrasyonlarda genellikle sırt derisine uygulanmasıyla yapılır. Değişik maddelerden oluşan, ülkeye veya bölgelere özgü farklı standart seriler bulunmaktadır3-5.

Bu çalışmada, Yozgat ilinde yaşayan ve Bozok Üniversitesi Tıp Fakültesi Dermatoloji Polikliniğine başvuran, alerjik kontakt dermatit ön tanısı düşünülerek 28 maddelik Avrupa standart serisi (ASS) ile yama testi yapılan hastalarda en sık rastlana kontakt alerjenleri ve özelliklerini tespit etmek amacıyla, Ocak 2011-Ekim 2012 tarihleri arasında yapılan yama testi sonuçları retrospektif olarak değerlendirildi.

\section{Gereç ve Yöntem}

Bozok Üniversitesi Tıp Fakültesi, Dermatoloji Anabilim Dalı́na Ocak 2011-Ekim 2012 tarihleri arasında başvuran, dermatolojik muayenesi AKD ile uyumlu olan 94 kadın, 74 erkek toplam 168 olgunun yama testleri sonucu retrospektif olarak değerlendirildi. Alerjik kontakt dermatit tanısı anamnez ve dermatolojik muayene verilerine göre ile klinik olarak konuldu. Test uygulanacak olgular uygulama bölgesine en az 1 hafta öncesinden topikal kortikosteroid içeren ilaçlar ve en az 3 hafta öncesinden sistemik kortikosteroid, nonsteroid antiinflamatuvar ve antihistamin kullanmadılar. İmmünsüpresif veya sitostatik ilaç kullanan ve yama testi sonucunu etkileyebilecek hastalığı olan olgulara test uygulanmadı. Olgulara yama testi olarak Uluslararası Kontakt Dermatit Araştırma Grubu'nun (ICDRG) önerdiği konsantrasyon ve taşıyıcılarda hazırlanan 28 maddelik ASS kullanıldı.
Test yapılmadan önce olguların sırt derisi \%70 alkol ile temizlenip kuruması beklendi. Alerjenler $1 \mathrm{~cm}^{2}$ lik kurutma kağıtlarına yerleştirilerek veya emdirilerek sırt bölgesine hipoalerjik bir flasterler ile her birinde 10 tane olacak şekilde sırt bölgesine uygulandı. Olgular banyo yapmamaları, aşırı terlemeye neden olacak aktivitelerden uzak durmaları ve testin yanlış değerlendirilmesine neden olacak ilaçları kullanmamaları konusunda uyarıldı. Flasterler 48 saat sonra açıldı ve 20 dakika bekledikten sonra ilk ve 72 . saatte ikinci değerlendirme ICDRG'nun önerdiği şemaya göre yapıldı ${ }^{1}$. 48. saatte pozitif olan ve 72 . saatte negatifleşen veya azalan reaksiyonlar iritan olarak kabul edildi.

Verilerin değerlendirilmesinde SPSS (Statistical Package for the Social Sciences) 18.0 istatistik programı kullanıldı. Sonuçların karşılaştırmasında ki-kare testi kullanıldı ve $0,05^{\prime}$ in altındaki $p$ değeri anlamlı kabul edildi.

\section{Bulgular}

Değerlendirmeye alınan toplam 168 olgunun 94'ü (\%56) kadın, 74'ü (\%44) erkek idi. Olguların yaşları 7-63 arasında olup, ortalama $34,1 \pm 14,9$ olarak saptandı ve yaş gruplarına göre dağılımı; 1-15 yaş $\% 9,5,16-45$ yaş \%64,3, 46-65 yaş \%26,2 idi.

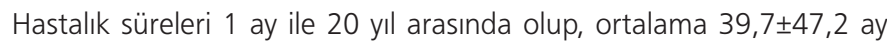
olarak belirlendi.

Ev hanımları $(\% 33,3)$, öğrenciler $(\% 17,9)$ ve işçilerin $(\% 15,5)$ en büyük meslek gruplarını oluşturduğu gözlendi.

En sık kontakt dermatit yerleşimi gözlenen el bölgesinde tutulum bulunan $96(\% 57,1)$ olgunun $66^{\prime}$ sında $(\% 39,3)$ yalnızca el tutulumu vardı. Bunu $46(\% 27,4)$ olgu ile yüz ve $18(\% 10,7)$ olgu ile el-yüz tutulumu izliyordu.

ASS ile deri yama testi yapılan 168 hastanın $86^{\prime}$ sında $(\% 51,1)$ en az bir pozitif reaksiyon saptandı. Bunların 54'ünde tek bir alerjene karşı, 32'sinde birden fazla alerjene karşı duyarlanma mevcuttu. Kadınların \%58, 1'inde, erkeklerin ise \%41,9'unda en az bir maddeye karşı pozitif reaksiyon saptandı. Cinsiyete göre pozitif reaksiyon verme yönünden istatistiksel olarak anlamlı bir fark saptanmadı $(p=0,6)$. Tablo 1'de ASS alerjenleriyle yapılan deri yama testi sonuçları verilmiştir. Çalışmamızda en sık duyarlanma nikel sülfata bağlı olarak saptanmıştır $(\% 20,2)$. Daha sonra sırasıyla potasyum dikromat $(\% 8,3)$, kobalt klorit $(\% 7,1)$, koku karışımı $(\% 7,1)$ ve parafenilendiamin (PPD) baz (\%6) en sık pozitif reaksiyon veren alerjenler olarak belirlenmiştir. En sık reaksiyon gözlenen alerjenler kadınlarda nikel sülfat, kobalt klorit ve koku karışımı iken, erkeklerde sıralama potasyum dikromat, nikel sülfat ve PPD baz şeklinde idi. Tablo 2'de en sık pozitif reaksiyon veren maddeler ve cinsiyete göre dağılımı verilmiştir. 
Tablo 1. Deri yama testi sonuçları

\begin{tabular}{|c|c|c|}
\hline Alerjen & $\begin{array}{l}\text { Reaksiyon } \\
\text { görülen has- } \\
\text { ta sayısı }\end{array}$ & $\%$ \\
\hline Potasyum dikromat & 14 & 8,3 \\
\hline Parafenilendiamin baz & 10 & 6 \\
\hline Tiuram karışımı & 4 & 2,4 \\
\hline Neomisin sülfat & 2 & 1,2 \\
\hline Kobalt klorit & 12 & 7,1 \\
\hline Benzokain & 4 & 2,4 \\
\hline Nikel sülfat & 34 & 20,2 \\
\hline Kliokinol & 0 & 0 \\
\hline Kolofoni & 4 & 2,4 \\
\hline Paraben karışımı & 6 & 3,6 \\
\hline N-izopropil-N-fenil-4-fenilendiamin & 6 & 3,6 \\
\hline Yün alkolleri & 6 & 3,6 \\
\hline Merkapto karışımı & 4 & 2,4 \\
\hline Epoksi reçine & 2 & 1,2 \\
\hline Peru balsamı & 4 & 2,4 \\
\hline 4-tert-Butilfenolformaldehit reçineleri & 2 & 1,2 \\
\hline Merkaptobenzotiazol & 4 & 2,4 \\
\hline Formaldehit & 6 & 3,6 \\
\hline Koku karışımı 1 & 0 & 0 \\
\hline Seskuiterpenlakton karışımı & 2 & 1,2 \\
\hline Kuaternium-15 & 6 & 3,6 \\
\hline Primin & 2 & 1,2 \\
\hline 5-kloro-2-metil-4-izotiazol-3-1 & 2 & 1,2 \\
\hline Budesonid & 2 & 1,2 \\
\hline Tiksokortol-21-pivalat & 4 & 2,4 \\
\hline Metildibromoglutaronitril & 0 & 0 \\
\hline Koku karışımı 2 & 12 & 7,1 \\
\hline "Lyral" & 2 & 1,2 \\
\hline
\end{tabular}

(Avrupa standart serisiyle en sık pozitif reksiyon saptanan 5 alerjen koyu renkle gösterilmiştir.)
En az bir alerjene pozitif reaksiyon verenlerin \%37,5'ini 1-15 yaş, \%59,3'ünü 16-45 yaş ve \%36,4'ünü de 46-65 yaş arasındaki olgular oluşturmakta idi. En az bir pozitif reaksiyon görülme sıklığı açısından yaş grupları arasında istatistiksel olarak anlamlı fark saptandı $(p=0,02)$. En sık pozitif reaksiyon veren maddeler ve yaş gruplarına göre dağılımı Tablo 3'de verilmiştir.

Yama testinde en sık pozitiflik saptadığımız alerjenlerin meslek gruplarına göre dağılımı Tablo 4'de görülmektedir. Nikel sülfat ve kobalt klorite karşı en fazla ev hanımlarında, potasyum dikromata karşı işçilerde, koku karışımına karşı öğrencilerde pozitif alerjik reaksiyon gözlendi.

\section{Tartışma}

AKD tanısı için altın standart tanı yöntemi yama testidir ve yüz yıldan fazla bir süredir kullanılmaktadır2. Yapılan çalışmalar bir hastanın kontakt alerjenlerini uygun ve tam anlamılla değerlendirmek için olguların sadece \%29-54'ünde anamnezin tek başına yeterli olabildiğini göstermiştir6. Deri yama testi kişinin belirli bir maddeye kontakt duyarlıığının olduğunun gösterilmesi ve hastanın anamnezinde bildirmediği, gözden kaçabilecek alerjenlerin ortaya çıkarılabilmesi açııından son derece faydalıdır. Günümüzde bilinen alerjen sayısının 3000'den fazla olduğu tahmin edilmektedir. Buna rağmen AKD'nin \%80'inden sadece 15-20 alerjen sorumludur. Bu nedenle en sık duyarlılığa neden olduğu gösterilmiş 20-25 alerjenin yer aldığı standart yama test serileri geliştirilmiştir ${ }^{3}$. Farklı merkezlerden ve coğrafik bölgelerden yapılan çeşitli çalışmaların sonucunda değişik seriler elde edilmiştir. Merkezler arasındaki farlı sonuçlarda o bölgenin demografik özellikleri ve hastaların klinik özelliklerinin farklılı̆ının önemli bir rol oynadığı düşünülmektedir. Maruz kalınan alerjenler bölgeden bölgeye değişmekte, hayat tarzı, yerel endüstri varlığı ve tedavi uygulamalar sonucu etkilemektedir. Bu farkllıklar nedeniyle en sık rastlanan tetikleyici alerjen değişebilmektedir7,8. Günümüzde birbirinden bağımsız çalışan 3 majör grup tarafından önerilen üç ayrı standart seri vardır ${ }^{9}$. Bunlar European Environmental and Contact Dermatitis Research Group (EECDRG) tarafından önerilen ASS, North American Contact Dermatitis grubu tarafından önerilen Amerikan standart serisi ve Japanese Society for Contact Dermatitis tarafından önerilen Japon standart serisidir. Avrupa ülkeleri gibi ülkemizde de Uluslararası Kontakt Dermatit Araştırma Grubu (ICDRG) ile Avrupa Çevre ve Kontakt Dermatit Araştırma Grubu (EECDRG)'nun ortak işbirliğiyle oluşturulan ASS kullanıımaktadır. Standart seriler, düzenli olarak yapılan uluslararası kontakt dermatit grup toplantılarında değerlendirilmekte ve içerik sürekli yenilenebilmektedir. Eğer bir alerjenin pozitif reaksiyon sıklığı \%1'in altında bulunursa, standart seriden çıkarılabilmektedir10. Çalışmamızda ASS ile yama testi uygulanan hastaların \%56'sının kadın ve ortalama yaşın 34,1 yıl olması bölgemizde AKD'in daha çok

Tablo 2. Sık pozitif reaksiyon veren alerjenler ve cinsiyete göre dağılımı

\begin{tabular}{|c|c|c|c|c|}
\hline Alerjen & Toplam (\%) & Erkek (\%) & Kadın (\%) & p \\
\hline Nikel sülfat & $34(20,2)$ & $10(13,5)$ & $24(25,5)$ & $>0,05$ \\
\hline Potasyum dikromat & $14(8,3)$ & $12(16,2)$ & $2(2,1)$ & $<0,05$ \\
\hline Kobalt klorit & $12(7,1)$ & $6(8,1)$ & $6(6,4)$ & $>0,05$ \\
\hline Koku karışımı 2 & $12(7,1)$ & $6(8,1)$ & $6(6,4)$ & $>0,05$ \\
\hline Parafenilendiamin baz & $10(6)$ & $8(10,8)$ & $2(2,1)$ & $<0,05$ \\
\hline
\end{tabular}


kadınlarda ve genç-orta yaş grubunda görüldüğünü göstermektedir. Yüz altmış sekiz hastanın 86 'sında $(\% 51,1)$ en az bir pozitif reaksiyon saptandı. Bunların 54'ünde tek bir alerjene karşı, 32'sinde birden fazla alerjene karşı duyarlanma mevcuttu. En az bir alerjene pozitif reaksiyon verenlerin \%59,3'ünü 16-45 yaş arasındaki olgular oluşturmakta idi. Bu yüksek oran aktif olarak çalışma hayatına devam eden kişilerin bu yaş grubunda daha fazla olması ile açıklanabilir. Ülkemizde Avrupa standart seri alerjenleri kullanılarak yapılan çalışmaların sonuçlarına göre en az bir alerjene karşı pozitif reaksiyon görülme oranı \%31,3 ile \%56,6 arasında değişmektedir ${ }^{11-18}$. Hastalarımızda diğer çalışmalarla uyumlu olarak lezyonların en sık ellerde $(\% 57,1)$ görüldüğü saptandı8,11-18. Çalışmamızda en sık duyarlanma nikel sülfata bağlı olarak saptanmıştır $(\% 20,2)$. Daha sonra sırasıyla potasyum dikromat $(\% 8,3)$, kobalt klorit $(\% 7,1)$, koku karışımı $(\% 7,1)$ ve PPD baz $(\% 6)$ en sık pozitif reaksiyon veren alerjenler olarak belirlenmiştir. Nikel, birçok alaşım ve kimyasal bileşikte bulunan bir metaldir, insanlar sürekli olarak bu metalle farklı oranlarda temas halindedir. Nikel, standart seride en sık saptanan alerjendir ve duyarlanma kadınlarda daha fazladır. Çalışmamızda nikel alerjisi kadınların \%25,5'inde varken, erkeklerin \%13,5'inde saptandı. Yapılan çalışmalarda nikel alerjisi oranı \%12-24,3 arasında değişmektedir11-18. Duyarlanmanın en sık sebebinin küpe takmak amacı ile kulakların delinmesi olduğu düşünülmektedir. Nikel alerjisi yaşlı kadınlarda daha az, genç kadınlarda daha fazla görülmektedir. Gençlerin daha çok nikel içeren ucuz takı kullanmalarının bu durum üzerine etkili olduğu düşünülmektedir3,10. Çalışmamızda da nikel alerjisi en çok 16-45 yaş grubunda $(\% 27,8)$ görülmekteydi.

Kromatlar başlıca çimento, beton ve diğer yapı malzemelerinde bulunur. Günümüzde potasyum dikromat duyarlılı̆ının en sık nedenini çimento ve harç ile temas oluşturmaktadır. Bu nedenle genellikle inşaat işinde çalışanlarda görülmektedir. Gelişmekte olan ülkelerde inşaat sektöründeki ilerlemeye paralel olarak kromat duyarlılığının da arttığı bildirilmektedir8,10. Çalışmamızda potasyum dikromat \%8,3 ile ikinci en sık görülen alerjen olarak belirlendi. Duyarlanma erkeklerde istatiksel olarak anlamlı derecede yüksek bulundu $(p<0,05)$. Ülkemizden yapılan araştırmalarda da potasyum dikromat duyarlanmasının ilk 3 sıra içinde olduğu görülmektedir. Ülkemizden bildirilen sonuçlara göre potasyum dikromat ile duyarlanma oranı $\% 2,2$ ile 16,5 arasında değişmektedir11-18. Ülkemizde 2000 yılından önce yapılan araştırmalarda kromat duyarlanmasının \%12-21 gibi yüksek oranlarda olduğu görülmekte ve oranın giderek azaldığı anlaşılmaktadır ${ }^{14,19}$. Son zamanlarda çimento yapımında üç değerlikli ferroz sülfat kullanımının artması duyarlanmanın azalmasını sağlamıştır. Çalışmamızda da potasyum dikromatın özellikle erkek işçi olgularda pozitif saptanmas literatür ile uyumlu bulundu.

Kobalt klorid çalışmamızda \%7,1 ile üçüncü sıklıkla görülen alerjen olarak belirlendi. Kobalt doğada genellikle nikelle veya kromla birlikte bulunan bir metaldir. Kobalt duyarlılı̆ı kadınlarda nikel, erkeklerde ise krom duyarlıığı ile birlikte bulunur ${ }^{10}$. Ülkemizde yapılan araştırmalarda kobalt klorid duyarlanmasını Akasya-Hillenbrand \%8,5, Akyol ve ark. \%5,3, Doğramacı ve ark. \%4,4, Ada ve ark. \%7,2, Koca ve ark. $\% 9,2$ olarak bildirmişlerdir11-13,16,18. Çalka ve ark. ise daha yüksek bir oranda $(\% 12,3)$ kobalt ile duyarlanma saptamışlardır17. Meslek grubu olarak kobalt kloride bağlı duyarlılık sıklıkla polyester reçine ve boyaların imalinde çalışanlarda, metal iş̧̧ilerinde ve çimento ile mesleği gereği teması olan kişilerde görülmektedir. Kadınlar nikel, kobalt ve potasyum dikromat gibi metallerin karışımı ile üretilen metal eşyaların teması sonucu kobalt klorid ile duyarlanmaktadırlar10,18.

Araştırmamızda koku karışımına karşı duyarlanma \%7,1 oranında

Tablo 3. Sık pozitif reaksiyon veren alerjenler ve yaş gruplarına göre dağıımı

\begin{tabular}{|l|c|c|c|c|c|}
\hline Alerjen & Toplam (\%) & $\mathbf{1 - 1 5}$ yaş & $\mathbf{1 6 - 4 5}$ yaş & $\mathbf{4 6 - 6 5}$ yaş & $\mathbf{p}$ \\
\hline Nikel sülfat & $34(20,2)$ & $2(12,5)$ & $30(27,8)$ & $2(4,5)$ & $<0,05$ \\
\hline Potasyum dikromat & $14(8,3)$ & $2(12,5)$ & $10(9,3)$ & $2(4,5)$ & $>0,05$ \\
\hline Kobalt klorit & $12(7,1)$ & $0(0)$ & $10(9,3)$ & $2(4,5)$ & $>0,05$ \\
\hline Koku karışımı 2 & $12(7,1)$ & $2(12,5)$ & $8(7,4)$ & $2(4,5)$ & $>0,05$ \\
\hline Parafenilendiamin baz & $10(6)$ & $2(12,5)$ & $6(5,6)$ & $2(4,5)$ & $>0,05$ \\
\hline
\end{tabular}

Tablo 4. Sık pozitif reaksiyon veren alerjenler ve meslek gruplarına göre dağılımı

\begin{tabular}{|c|c|c|c|c|c|}
\hline Meslekler & $\begin{array}{l}\text { Nikel sülfat } \\
\text { n (\%) }\end{array}$ & $\begin{array}{c}\text { Potasyum dikromat } \\
\mathrm{n}(\%)\end{array}$ & $\begin{array}{c}\text { Kobalt klorit } \\
\text { n (\%) }\end{array}$ & $\begin{array}{c}\text { Koku karışımı } \\
\text { n (\%) }\end{array}$ & $\begin{array}{c}\text { Parafenilendiamin baz } \\
\mathrm{n}(\%)\end{array}$ \\
\hline Ev hanımı & $14(25)$ & $0(0)$ & $4(7,1)$ & $2(3,6)$ & $0(0)$ \\
\hline İşçi & $6(23,1)$ & $4(15,4)$ & $2(7,7)$ & $0(0)$ & $2(7,7)$ \\
\hline Emekli & $0(0)$ & $2(33,3)$ & $0(0)$ & $2(33,3)$ & $0(0)$ \\
\hline Büro çalışanı & $0(0)$ & $0(0)$ & $0(0)$ & $2(12,5)$ & $0(0)$ \\
\hline Öğrenci & $6(20)$ & $2(6,7)$ & $2(6,7)$ & $4(13,3)$ & $0(0)$ \\
\hline Öğretmen & $4(33,3)$ & $2(16,7)$ & $2(16,7)$ & $2(16,7)$ & $2(16,7)$ \\
\hline Sağlık çalışanı & $4(100)$ & $0(0)$ & $0(0)$ & $0(0)$ & $0(0)$ \\
\hline Tamirci & $0(0)$ & $2(100)$ & $0(0)$ & $0(0)$ & $0(0)$ \\
\hline Kuaför & $0(0)$ & $0(0)$ & $0(0)$ & $0(0)$ & $2(50)$ \\
\hline Diğer & $0(0)$ & $2(16,7)$ & $2(16,7)$ & $0(0)$ & $4(33,3)$ \\
\hline Toplam & $34(20,2)$ & $14(8,3)$ & $12(7,1)$ & $12(7,1)$ & $10(6)$ \\
\hline
\end{tabular}


görüldü. Bu oran Türkiye'den bildirilen diğer çalışmalardan11-18 $(\% 2-\% 5,5)$ daha yüksek iken Avrupa verilerine21 $(\% 6,6)$ daha yakın bulunmuştur. Bunun nedeni son yıllarda kozmetik, parfüm ve medikal ürünlerin kullanımının artmasına bağlı olabilir.

PPD ile duyarlanma $\% 6^{\prime}$ lık oran ile ülkemizde yapılan çalışmaların sonucuna göre daha yüksek bulunmuştur. Akasya-Hillenbrand \%3,7, Akyol ve ark. \%1,8, Doğramacı ve ark. \%1,3, Ada ve ark. \%2,6, Çalka ve ark. \%1,8, Koca ve ark. \%1,6 olarak bildirmişlerdir11-13,16-18. PPD özellikle siyah saç boyalarında kullanılan renksiz bir bileşiktir. Bu maddeye karşı kontakt duyarlanma en sık mesleksel olarak berberlerde veya saç boyası ile temas eden kimselerde oluşur ${ }^{10}$. PPD ile pozitif reaksiyon veren olgularımızın \%20'sini kuaförler oluşturmaktaydı. Ayrıca kürk boyası ve matbaa mürekkebinde, deri işleme, lastik vulkanizasyonu, litografi ve fotoğrafçוlıkta da kullanılabilmektedir. PPD geçici dövmelerde kına ile karıştırılarak hint kınası adı altında uygulanmaktadır. Özellikle yaz aylarında gençler arasında kullanımı çok yaygındır. Ülkemizde PPD alerjik olgular artan sayıda bildirilmektedir. Aileler ve alerjik olgular PPD reaksiyonu açısından bilgilendirilmelidir ${ }^{3}$. Bölgemizde hint kınası kullanımının yaygın olması PPD duyarlanma oranında yüksekliğe neden olmuş olabilir.

Çalışmamızda belirlenen ilk 5 ASS alerjeni, Akasya ve ark.'nın çalışması dışında Tükiye'nin çeşitli bölgelerindeki merkezlerden, değişik zaman dilimlerinde yapılan benzer nitelikteki diğer serilerden farklılık göstermektedir11-18. Akasya ve ark.'nın çalışması ile bizim çalışmamız da, diğer serilerden farklı olarak, potasyum dikromat ikinci sık görülen alerjen olarak saptanmıştır ${ }^{11}$. Ankara'da yapılan başka bir çalışmada neomisin sülfat; Aydın'da yapılan çalışmada formaldehit, 5-kloro-2metil-4-izotiazol-3-1 ve lanolin; İstanbul'da yapılan çalışmada kolofoni ve butilfenolformaldehit reçinesi; Van'dan yapılan çalışmada da paraben karışımı en sık rastlanan 5 alerjen arasında bulunmuştur'2,14,15,17. Öte yandan, Ankara, Hatay ve Zonguldak illerinden bildirilen üç ayrı çalışmada, 12,13,18 Peru balsamının; İstanbul ve Van'dan bildirilen çalışmalarda, 15,17 tiuram karışımının ilk 5 alerjen arasında yer aldığı görülmektedir.

Çalışmamızda kliokinol ve metildibromoglutaronitril ile hiçbir hastada pozitif reaksiyon saptamadık. Ülkemizde yapılan bir araştırmada maliyeti düşürmek ve kontakt duyarlanmayı azaltmak amacı ile en sık alerjenlerden oluşan küçük bir alerjen serisi ile alerji testi yapılması önerilmektedir20. Ancak bir alerjen bir ülkede veya bölgede herhangi bir duyarlanma yapmasa da bir başka bölgede sık rastlanan bir alerjen olabilmektedir. Bu nedenle bazı otörler rutin olarak AKD'li hastalarda ASS'nin kullanılmasını tavsiye etmektedir ${ }^{3}$. Uygulanan maddelere rağmen pek çok hastada negatif sonuç elde edilebilmektedir. Çalışmamızda ASS ile hastaların \%48,8'inde hiçbir maddeye karşı reaksiyon saptanmadı.

Sonuç olarak, bölgemizde daha önce benzer bir çalışma yapılmamış olması nedeni ile çalışmamız Yozgat ilinde AKD tanısıyla deri yama testi yapılan hastaların kontakt alerjen profili hakkında bilgi vermektedir.
ASS ile en sık saptanan alerjenler ve sıklık oranları, Türkiye'nin çeşitli illerindeki merkezler arasında değişkenlik göstermektedir. Kontakt alerjen profilindeki bölgesel farklııkların, aynı zaman diliminde ve benzer hasta profilnde yapılacak yeni çalışmalarla değerlendirilmesi sonucunda ülkemize ait bir standart seri oluşturulabilir.

\section{Kaynaklar}

1. Harmanyeri $Y$, Taşkapan O: Allerjik kontakt dermatit. Dermatololoji. Ed. Tüzün Y, Gürer MA, Serdaroğlu S, Oğuz O, Aksungur VL. 3'üncü Baskı, İstanbul, Nobel Tıp Kitabevleri, 2008;201-34.

2. Mowad CM: Patch testing: pitfalls and performance. Curr Opin Allergy Clin Immünol 2006;6:340-4.

3. Önder M: Allerjik kontakt dermatitler. Türkderm 2009;43:3-9.

4. Douglas JD: Allergic contact dermatitis. Dermatol Nurs 2009;2:287-91.

5. Alper S, Ertam i: Allerjik kontakt dermatit. Turk Klin J Int Med Sci 2006;2:3-8.

6. Belsito DV: The diagnostic evaluation, treatment, and prevention of allergic contact dermatitis in the new millennium. J Allergy Clin Immünol 2000;105:409-20.

7. Schnuch A, Geier J, Uter W, et al: National rates and regional differences in sensitization to allergens of the standard series. Population-adjusted frequencies of sensitization (PAFS) in 40,000 patients from a multicenter study (IVDK). Contact Dermatitis 1997:37:200-9.

8. Uter W, Rämsch $C$, Aberer $W$, et al: The European baseline series in 10 European Countries, 2005/2006-results of the European Surveillance System on Contact Allergies (ESSCA). Contact Dermatitis 2009;61:31-8.

9. Lachapelle JM, Ale SI, Freeman S, et al: Proposal for a revised international standard series of patch tests. Contact Dermatitis 1997;36:121-3.

10. Akasya E, Özkaya-Bayazıt E: Avrupa standart yama testi serisi. Türkderm 2001;35:265-76.

11. Akasya-Hillenbrand E, Ozkaya-Bayazit E: Patch test results in 542 patients with suspected contact dermatitis in Turkey. Contact Dermatitis 2002;46:17-23.

12. Akyol A, Boyvat A, Peksari $Y$, Gürgey E: Contact sensitivity to standard series allergens in 1038 patients with contact dermatitis in Turkey. Contact Dermatitis 2005;52:333-7.

13. Doğramacı $A C ̧$, Gürer MA: Kontakt dermatitli hastalarda yama testi sonuçları: Beş yıllık retrospektif çalışma. Turk Klin J Dermatol 2008;18:215-22.

14. Şendur N, Karaman G, Akyıldız Ü, Şavk E: Kontakt dermatitli 1 hastanın yama testi sonuçlarının değerlendirilmesi. Turk Klin J Dermatol 2001;11:11-5.

15. Su Ö, Onsun N, Özkaya DB, et al: Alerjik kontakt dermatit / mukoziti olan hastaların yama testi sonuçları. Türkderm 2008;42:13-7.

16. Ada S,Aşkın Ü, Güleç AT, Seçkin D: Alerjik kontakt dermatit tanısıyla deri yama testi yapılan 775 hastanın sonuçları. Türkderm 2010;44:187-92.

17. Çalka Ö, Karadağ AS, Akdeniz N, Bilgili SG: Türkiye'nin doğusunda kontakt dermatitli hastalarda deri yama testi sonuçları. Türkderm 2011;45:19-23.

18. Koca R, Altınyazar C, Solak Tekin N, et al: Batı Karadeniz Bölgesinde alerjik kontakt dermatitli olgularda yama testi sonuçları: Beş yıllık retrospektif çalışma. Türkderm 2011;45:198-202.

19. Tunalı Ş, Acar A, Sarıcaoğlu H, Palalı Z, Tokgöz N: Kontakt dermatitli 400 hastada yama testi sonuçları. T Klin Dermatoloji 1995;5:71-7.

20. Demirgüneş FE, S Ersoy Evans, Boztepe G, Atakan N: Deri yama testi: daha az madde içeren ön yama testi serisi daha pratik olabilir mi? Türkderm 2007;41:7-10.

21. Uter W, Geier J, Frosch $P$, Schnuch A: Contact allergy to fragrances: current patch test results (2005-2008) from the Information Network of Departments of Dermatology. Contact Dermatitis 2010;63:254-61. 